\title{
Four natriuretic peptides (ANP, BNP, VNP and CNP) coexist in the sturgeon: identification of BNP in fish lineage
}

\author{
A Kawakoshi, S Hyodo, K Inoue, Y Kobayashi ${ }^{1}$ and $\mathbf{Y}$ Takei \\ Ocean Research Institute, University of Tokyo, Tokyo 164-8639, Japan \\ ${ }^{1}$ Center for Integrated Research in Science, Shimane University, Izumo 693-8501, Japan \\ (Requests for offprints should be addressed to A Kawakoshi, Laboratory of Physiology, Department of Marine Bioscience, Ocean Research Institute, \\ University of Tokyo, 1-15-1 Minamidai, Nakano, Tokyo 164-8639, Japan; Email: kawakosi@ ori.u-tokyo.ac.jp)
}

\begin{abstract}
The natriuretic peptide (NP) family is composed of three members: atrial, brain/ventricular and C-type NPs (ANP, BNP/VNP and CNP respectively) in tetrapods and teleostean fish, but only CNP in elasmobranch fish. In order to trace the process of divergence of the NP family in early vertebrate evolution, we attempted to detect NPs in the primitive ray-finned fish, the sturgeon (Acipenser transmontanus). Unexpectedly, we isolated four distinct NP cDNAs from the heart and brain of this chondrostean fish. The single NP from the brain was CNP, as judged from the lack of C-terminal 'tail' sequence extending from the intramolecular ring. Two of the three cardiac NPs were ANP and VNP, as judged by the presence of an amidation signal at its C-terminus (ANP) and a long and conserved C-terminal tail sequence (VNP) respectively. The third cardiac NP was most probably BNP because it possessed all the features characteristic of BNP including: (1) the presence of dibasic amino acids within the intramolecular ring; (2) the presence of AUUUA repeats in the $3^{\prime}$-untranslated region of its mRNA; (3) equivalent expression of its mRNA in the atrium and ventricle and appreciable expression in the brain. Based on the sturgeon BNP sequence, we further isolated BNP cDNA from the heart of tilapia and pufferfish for the first time in teleostean fish. Phylogenetic analysis of the precursors showed that newly identified NPs belong to each group of the four NPs. The current identification of both VNP and BNP in the sturgeon clearly showed that BNP and VNP are coded by distinct genes, and that the NP family consists of at least four members in the ray-finned fish. VNP has not been molecularly identified in mammals but its presence is suggested from physiological studies; heterologous fish VNP exhibited more potent vasorelaxant activity than homologous mammalian ANP in the isolated coronary artery of dogs.
\end{abstract}

Journal of Molecular Endocrinology (2004) 32, 547-555

\section{Introduction}

Natriuretic peptides $(\mathrm{NPs})$ comprise a hormone family that plays a pivotal role in cardiovascular and body fluid homeostasis in vertebrates (Brenner et al. 1990, Evans 1990, Farrell \& Olson 2000, Loretz \& Pollina 2000, Takei 2000). Atrial, brain and C-type NPs (ANP, BNP and CNP) have been identified in tetrapods that range from amphibians to mammals. While ANP and BNP are circulating hormones secreted from the heart, GNP appears to be a paracrine/autocrine factor in the brain and some peripheral tissues such as the endothelium (Chen \& Burnett 1998). The difference between
ANP and BNP is that the former is produced mainly in the atrium and secreted via a regulatory pathway in response to its stretch, but the latter is produced equally in the atrium and ventricle and secreted mostly via a constitutive pathway.

Three types of NPs have also been identified in several teleostean species (Takei \& Hirose 2002). However, BNP has not been identified yet and, instead, a novel type named ventricular NP (VNP) has been isolated from the cardiac ventricle of eel and trout (Takei et al. 1991, 1994). Since VNP exhibits unique characteristics in its structure and function compared with other NPs (Takei et al. 1991), VNP appears to be distinct from BNP. 
However, efforts to detect BNP in fish and VNP in mammals have not been successful. Therefore, it is generally believed that teleostean VNP is a homolog of tetrapod BNP.

We have been pursuing the molecular evolution of the NP family in vertebrates. In elasmobranchs, only GNP is present as a peptide and mRNA in the heart and brain of a few species (Suzuki et al. 1994, Kawakoshi et al. 2001). We also have shown that only a single NP, named EbuNP after its scientific name (Eptatretus burgeri), exists in the heart and brain of the most primitive vertebrate group, the hagfish (Kawakoshi et al. 2003). Therefore, the NP family has been diversified into ANP, VNP and GNP during the evolution to bony fishes, and VNP may have been replaced by BNP during the evolution to tetrapods. To delineate further the early evolutionary process to teleost, we attempted to determine NP cDNAs in the heart and brain of a primitive ray-finned fish with a PCR-based method using primers that can amplify all NPs thus far identified. We chose a chondrostean fish, the sturgeon (Acipenser transmontanus) because this fish group occupies more basal position than teleostean fish in the group of ray-finned bony fish, as shown by the morphology and molecular-based classification (Bemis et al. 1997, Inoue et al. 2003), and is distinct from the cartilaginous fish group such as elasmobranchs. Unexpectedly, we identified all four NPs, including BNP, in a single individual of this fish. Encouraged by this finding, intensive searches for BNP were carried out in the heart of pufferfish (Takifugu rubripes) and tilapia (Oreochromis mossambicus), resulting in the identification of $\mathrm{BNP}$ in these teleostean fishes.

These results clearly showed that BNP and VNP are not orthologs but are coded by distinct genes, and further suggest that VNP is present also in tetrapods. To test further the possible existence of VNP in mammals, we examined the vasorelaxant activity of fish VNP in an aortic ring preparation of dogs and compared the potency with that of mammalian ANP and BNP. Generally, heterologous fish NPs have much lower activity than the mammalian counterpart in mammals (Takei 2000).

\section{Materials and methods}

\section{Animals}

Fish experiments were performed in accordance with the Guidelines for Care and Use of Animals approved by the University of Tokyo, and dog experiments were performed by Shimane Medical University.

Male white sturgeon, Acipenser transmontanus, weighing $2 \cdot 8 \pm 0 \cdot 6 \mathrm{~kg}(n=3)$, were obtained from SUNROCK, Ltd (Kamaishi, Japan); pufferfish, Takifugu rubripes, were obtained from Oita Biological Technology Center, Nippon Suisan Kaisha (Tsurumi, Japan); tilapia, Oreochromis mossambicus, were from wild stocks in Okinawa, Japan. Fish were anesthetized in $0 \cdot 1 \%(\mathrm{w} / \mathrm{v}) 3$-aminobenzoic acid ethyl ester (Sigma) for $5 \mathrm{~min}$. Tissues (atrium, ventricle, brain, gill, kidney and intestine) were then dissected out, quickly frozen in liquid nitrogen and kept at $-80^{\circ} \mathrm{C}$ until use.

\section{RNA extraction}

Total RNA was extracted from the atrium, ventricle and brain of a single sturgeon and from the heart of a single pufferfish and tilapia using the AGPC method (Chomczynski \& Sacchi 1987). Poly- $\mathrm{A}^{+}$RNA was purified from the total RNA using Oligotex-dT30 (Takara, Kyoto, Japan).

\section{Cloning of sturgeon NP cDNAs}

The cloning of sturgeon NP cDNAs was achieved using 3'- and 5'-rapid amplification of cDNA ends (RACE) methodologies. One microgram of poly- $\mathrm{A}^{+}$RNA was reverse transcribed using the 3'-Full RACE Core Set (Takara). Three degenerate sense primers, which cover sequence variations in all known NP cDNAs, were designed: NP-1 for ANP and BNP, NP-2 for ANP and VNP, and NP-3 for CNP (Table 1). The validity of these primers has been tested by amplification of NP cDNAs from the heart and brain of the eel, quail and dogfish. PGR reactions were performed with one of the three sense primers and the universal antisense adaptor primer, using a high-fidelity DNA polymerase, Ex-Taq (Takara). After an initial denaturation at $94{ }^{\circ} \mathrm{C}$ for $3 \mathrm{~min}, 40$ cycles of PCR were performed, each consisting of $1 \mathrm{~min}$ denaturation at $94{ }^{\circ} \mathrm{C}, 30 \mathrm{~s}$ annealing at varying temperatures and $1.5 \mathrm{~min}$ extension at $72{ }^{\circ} \mathrm{C}$. The amplified products were ligated into a pT7 Blue $\mathrm{T}$-vector (Novagen, Madison, WI, USA). The nucleotide sequences were determined by an automated DNA sequencer (PRISM 310; Perkin-Elmer/ Applied Biosystems, Foster City, CA, USA). 
Table 1 Primer sequences used in this study

\section{Sequence}

$\begin{array}{ll}\text { Name } & \\ \text { NP-1 } & \text { 5'-GGCTGCTTTGGGSGNMGRATNGAYMGNAT-3' } \\ \text { NP-2 } & \text { 5'-GGCTGTTTTGGTGMNMGRATKGANMGNAT-3' } \\ \text { NP-3 } & \text { 5'-GGCTGCTTTGGCYTNAARCTGGACMGNAT-3' } \\ \text { ANP-S } & \text { 5'-AGTCATCTACACTGGAGTCC-3' } \\ \text { ANP-A } & \text { 5'-AGTGTTGATTCCTTCACCAC-3' } \\ \text { BNP-S } & \text { 5'-AACAGCGACGCTGTGGTCAG-3' } \\ \text { BNP-A } & \text { 5'-GACTCGAACGATGGTTTAAC-3' } \\ \text { VNP-S } & \text { 5'-TCTGAAGGATTTACTTGAGCG-3' } \\ \text { VNP-A } & \text { 5'-CCAAATCTGGAGTTGTTGCAC-3' } \\ \text { CNP-S } & \text { 5'-AACCACAAGAGCCAGCTGGC-3' } \\ \text { CNP-A } & \text { 5'-GAACATCTTCCGACTGCTCAT-3' } \\ \text { Act-S } & \text { 5'-GAAACCTTCAACACCCCAGC-3' } \\ \text { Act-A } & \text { 5'-TCAGGATCTTCATGAGGTAG-3' }\end{array}$

Complementary DNA for 5'-RACE was synthesized using the SMART cDNA Library Construction Kit (Clontech Laboratories, Palo Alto, CA, USA). Adaptor-ligated double-strand cDNA was reverse transcribed from $1 \mu \mathrm{g}$ poly- $\mathrm{A}^{+}$RNA, and was pre-amplified by the long distance-PCR protocol according to the manufacturer's instructions. PCR reactions were performed as described above with gene-specific antisense primers and the universal sense adaptor primer. PCR products were subcloned and sequenced as described above. Finally, full-length cDNAs were amplified with newly designed specific primers in the $5^{\prime}$ - and $3^{\prime}$ untranslated regions to confirm the sequences.

\section{Tissue distribution of sturgeon NP mRNAs}

Expression of the sturgeon NP genes was examined in the atrium, ventricle, brain, gill, kidney and intestine from three individuals. One microgram of total RNA from each tissue was used as template for synthesis of first-strand cDNA utilizing the Superscript First-Strand Synthesis System for RT-PCR (Invitrogen, Carlsbad, CA, USA). Onefortieth of the first-strand cDNA was subjected to PCR reaction with specific sense and antisense primers: ANP-S and ANP-A for ANP; BNP-S and BNP-A for BNP; VNP-S and VNP-A for VNP; GNP-S and CNP-A for GNP (Table 1). These specific primers were designed to adjust the length of PGR products, 444, 388, 303 and $249 \mathrm{bp}$ for ANP, BNP, VNP and CNP respectively, for visual distinction after electrophoresis. After an initial denaturation at $94{ }^{\circ} \mathrm{C}$ for $3 \mathrm{~min}, 30$ cycles of PCR were performed, each consisting of $1 \mathrm{~min}$ denaturation at $94{ }^{\circ} \mathrm{C}, 30 \mathrm{~s}$ annealing at $60{ }^{\circ} \mathrm{C}$ and $1.5 \mathrm{~min}$ extension at $72{ }^{\circ} \mathrm{C}$. As an internal control, sturgeon $\beta$-actin mRNA was amplified using sense (Act-S) and antisense (Act-A) primers (Table 1), by the same protocol. PCR products were electrophoresed in $1 \cdot 2 \%(\mathrm{w} / \mathrm{v})$ agarose gels and were detected by a fluorescence image analyzer (FLA 2000, Fuji Film, Tokyo, Japan) after staining with ethidium bromide.

\section{Cloning of pufferfish and tilapia NP cDNAs}

Since one of the NP cDNAs cloned from the heart of the sturgeon was that of $\mathrm{BNP}$, it may also be present in teleostean fishes even if it has not been identified yet. To test the possibility, NP cDNAs were cloned from the heart of pufferfish and tilapia using NP-1 primer as described above.

\section{Molecular phylogenetic analysis}

Deduced amino acid sequences of NP precursors of the sturgeon, pufferfish and tilapia were aligned with those of ANP, BNP, VNP and CNP of other species by the ClustalW program in a worldwide web server of the DNA Data Bank of Japan (http://www.ddbj.nig.ac.jp). The alignment was performed by default settings and errors in alignment were adjusted manually before analysis. The molecular phylogenetic tree was estimated by a neighbor-joining method in the ClustalW program with default settings.

\section{Vasorelaxant actions on dog arteries in vitro}

Mongrel dogs of both sexes $(5-18 \mathrm{~kg}, n=6)$ were anesthetized with sodium pentobarbital $(30 \mathrm{mg} / \mathrm{kg}$, i.v.) and exsanguinated. The renal and coronary arteries were dissected out, and ring preparations (4 $\mathrm{mm}$ in width) were cut and fixed vertically in organ baths containing Krebs-Henseleit buffer solution under $95 \% \mathrm{O}_{2}, \quad 5 \% \quad \mathrm{CO}_{2}$ at $37^{\circ} \mathrm{C}$. Isometric tension was measured using a transducer (Nihon Kohden Kogyo, Tokyo, Japan). Initial tension was set at $1.5 \mathrm{~g}$ for renal artery and $0.8 \mathrm{~g}$ for coronary artery. After equilibration for $1.5 \mathrm{~h}$, the rings were contracted with $10^{-5} \mathrm{M}$ prostaglan$\operatorname{din} \mathrm{F}_{2 \alpha}$, and cumulative concentration-response curves were constructed to human (canine) ANP, 
(a)

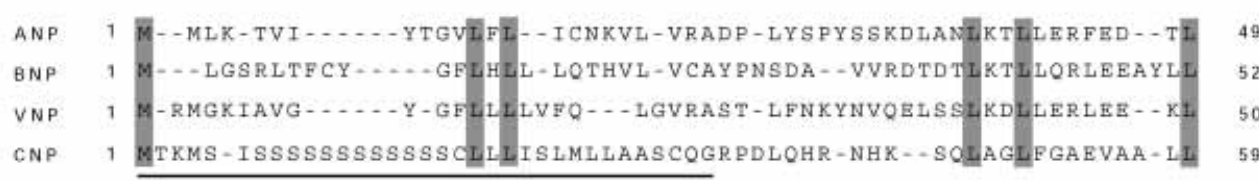

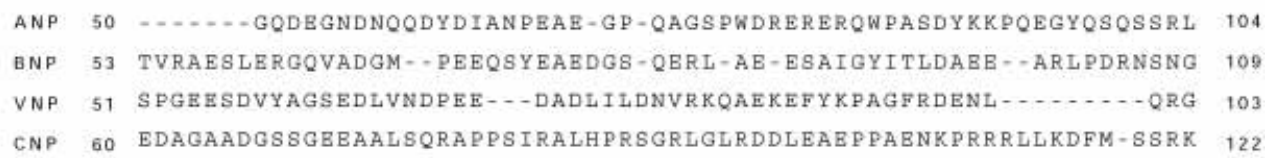

ANP 105 RDLLMAPRNNRGSSGCFGSRIDRIGSMSSMGC-GGSRKG 142

BNP 110 --FLNPLRNTKRYSGCFGRRLDRIG\$MSALGCNGGSRLSYKRS 150

VNP 104 R-LRSIATSARSMNGCPGNRIERIGSWSSLGCNN-SRFGSKKRIF 145

CNP 123 -MFRGRTKKMQQGRGCFGMKLDRIGSMSGLGC

(b)

$5^{\prime}$ aaccaucguucgaguccccuacuguacaccggcucuacggaaugcaauguggauuuuuucaag

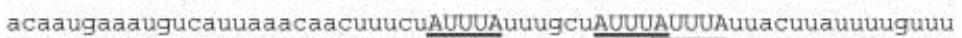
aaนAUUUA gauugcuguuuuaaacugcaauaacuguauuucaagucauuaaaaagcgauacaаuaacu cucuuuauuuagc-poly-A $3^{\prime}$

Figure 1 Sequence of NP precursors in the sturgeon. (a) Amino acid sequences of NP precursors deduced from the cloned cDNA. Amino acid residues identical to all NPs are shadowed. Predicted signal sequence is underlined. Mature peptides are deduced from the processing sites of other species and are indicated in bold. The disulfide bond is connected by a solid line. Numbers on both sides indicate the amino acid residues in the precursors. (b) Nucleotide sequence of the $3^{\prime}$-untranslated region of BNP mRNA. AUUUA repeats are indicated by capital letters and are underlined. Accession numbers: ANP, AB087728; BNP, AB087729; VNP, AB087730; CNP, AB087731.

human BNP and eel VNP (Peptide Institute, Osaka, Japan). The maximum relaxation induced by $10^{-4} \mathrm{M}$ papaverine was taken as $100 \%$.

\section{Results}

\section{Cloning of cDNAs encoding NP precursors from sturgeon}

Four NP cDNAs were cloned from the sturgeon, two from the atrium, one from the ventricle and one from the brain. Precursor sequences deduced from the cDNAs are shown in Fig. 1a. Each NP precursor carried a mature peptide with a ring structure flanked by a disulfide bond at the C-terminus. Judging from the similarity of amino acid sequences of mature peptides, one of the atrial NPs was determined as ANP, the one from the ventricle as VNP and the one from the brain as GNP (Fig. 2). The sturgeon ANP may have an amidated C-terminus as predicted from the presence of $\mathrm{C}$-terminal glycine. The sturgeon VNP had a long and conserved C-terminal 'tail' sequence extending from the intramolecular ring, but two amino acids were truncated from the C-terminus compared with other VNPs. The sturgeon CNP lacked the tail sequence as did all CNPs thus far identified (Fig. 2). The second atrial NP was determined as BNP based on the following criteria: (1) the presence of two consecutive basic amino acid residues (Arg-Arg) in the ring structure of the mature peptide; (2) the repeated AUUUA motifs in the 3 -untranslated region of its mRNA (Fig. 1b).

\section{Tissue distribution of sturgeon NP mRNAs}

RT-PGR using sturgeon tissues showed that ANP mRNA was expressed abundantly in the atrium, 

ANP
eel
SK S S P CF G K K D R I GSY S L L CN - S RK - NH2
trout
SKAVSGCFGARMDRIGTSSGLGCSPKRRS
sturgeon
pufferfish
NNRG S S GCF G S R I R I GSMS S M C G G S R K - NH2
tilapia
RKRASSCFGARMDRIGNASGLGCNNGR - NH2
RKR TS GCF GARMDR I GNASG L G CNSGR - NH2
BNP
pig
Xenopus
**
S P K TMRDSGCFGRRLDRIGSLSGLGCNVLRRY
NPKMMRGSGCFGRRIDRIDSLSGMGCNGSRRY
sturgeon
pufferfish
NTK - - RYSGCFGRRLDRIGSMSALGCNGGSRLSYKRS
tilapia
NDSSRRSSSCFGRRMDRIGSMSSIGCNTVGKYNPK
NDSSRRSSGCFGRRMDRIGSMSSLGCNTVGRYNPKQR
VNP $\begin{array}{r}\text { eel } \\ \text { trout } \\ \text { sturgeon }\end{array}$
CNP reel
sturgeon

\begin{abstract}
KSFNSCF GTRMDRIGSWSGLGCNSLKNGTKKKIFGN KSFNSCFGNRIERIGSWSGLGCNNVKTGNKKRIFGN
\end{abstract} RSMNG CF GNRIERIGSWSSLGCNNSRFGSKKRIF

\section{GWNRG CF GL K L DR I G S L S G L GC \\ GWNRG C F GLKLDRIGSMS GL GC}
MQQ GRG CF GMKL DR I GSMSGL G C

Figure 2 Amino acid comparison of deduced mature sequences of newly identified NPs of the sturgeon, pufferfish, tilapia with those of other species. Identical amino acid residues in each group are shadowed. The disulfide bond is connected by a solid line. Asterisks show the dibasic amino acid residues characteristic to BNP. The C-termini with potential amidation signals are shown in the amidated form. Accession numbers: pufferfish ANP, AB089933; pufferfish BNP, AB089934; tilapia ANP, AB087283; tilapia BNP, AB087284; eel ANP, AB019372; eel VNP, AB019371; eel CNP, D88022; trout ANP, AB076603; trout VNP, AB076604; trout CNP, AB076601; porcine BNP, M25547; Xenopus BNP, BG346231.

appreciably in the ventricle, but not in the brain (Fig. 3). BNP mRNA was expressed abundantly in the atrium and ventricle and appreciably in the brain. VNP mRNA was expressed similarly in the

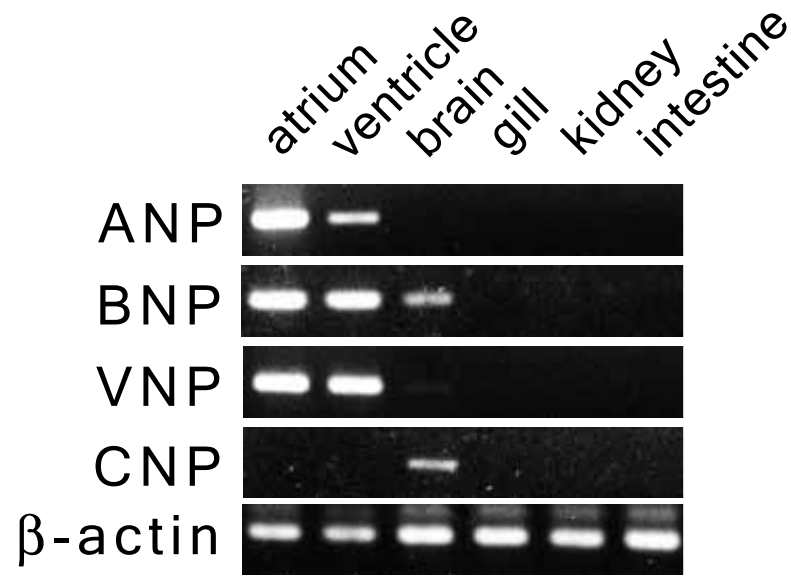

Figure 3 Expression of sturgeon NP genes in various tissues as determined by RT-PCR. PCR was run with $25 \mathrm{ng}$ total RNA and for 30 cycles. Sturgeon $\beta$-actin was used as an internal control. atrium and ventricle but only minutely in the brain. GNP mRNA was detected only in the brain. Each NP mRNA was not detected in the gill, kidney and intestine. The pattern of distribution of the four NPs was similar in the three fish examined.

\section{Cloning of NP cDNAs from pufferfish and tilapia}

BNP cDNA was cloned, in addition to that of ANP, from the heart of pufferfish and tilapia (Fig. 2). BNPs had two consecutive basic amino acid residues within the ring structure as did all BNPs thus far identified. ANPs of these teleostean fish possessed an amidation signal at the $\mathrm{C}$-terminus of the deduced mature peptide, as observed in the sturgeon and eel ANP.

\section{Molecular phylogenetic analysis}

The molecular phylogenetic tree estimated with the precursor sequences conformed to the above 


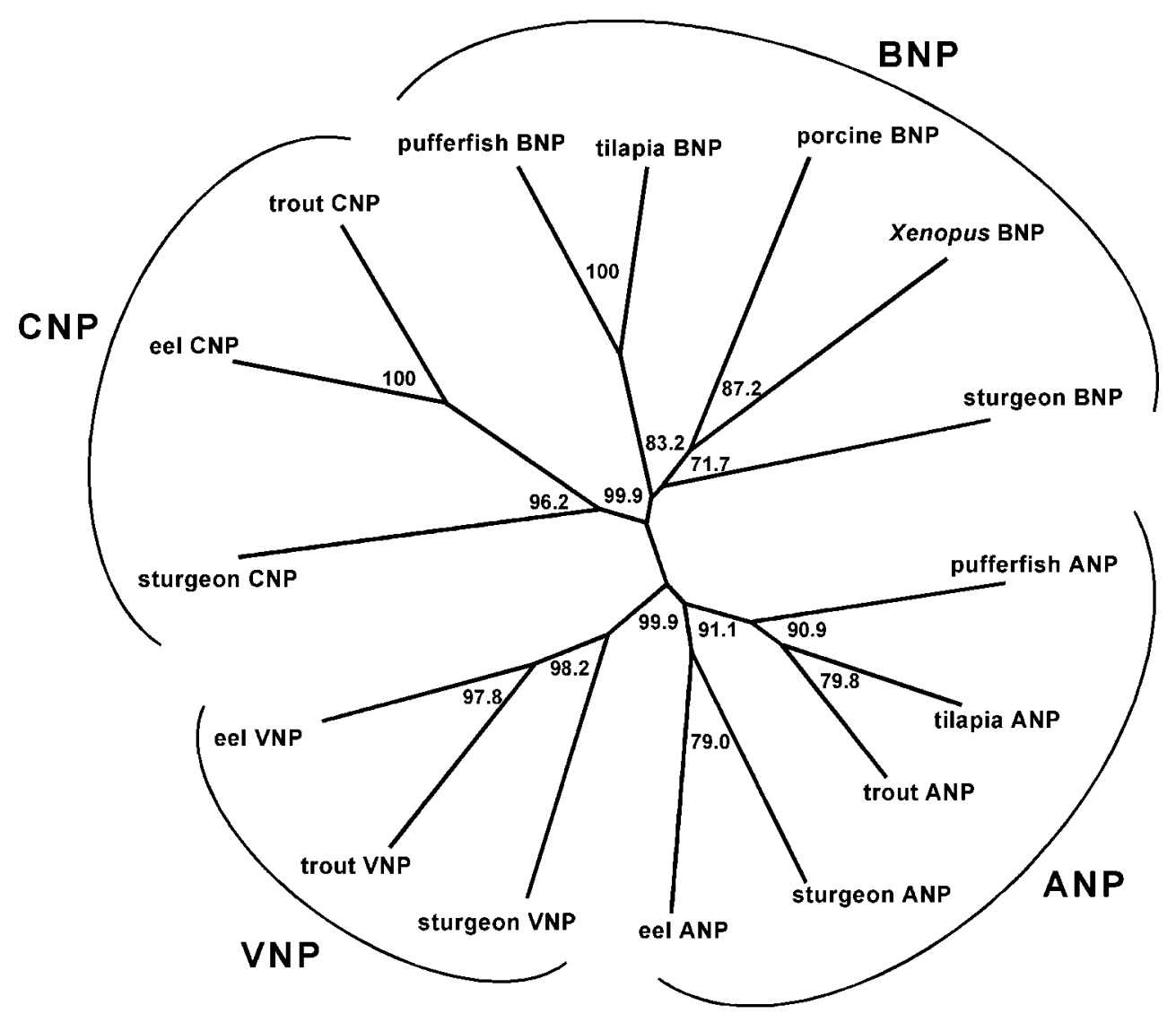

Figure 4 Phylogenetic analysis of NP precursors. The molecular phylogenetic tree was estimated by a neighbor-joining method in the ClustalW program. The numbers shown on the interior nodes are bootstrap values in per cent.

classification of NPs based on the mature sequence. As shown in Fig. 4, sturgeon ANP, BNP, VNP and CNP are grouped into the respective NPs of other species. ANP and BNP of the pufferfish and tilapia were also included in the ANP and BNP groups respectively (Fig. 4).

\section{Vasorelaxant effects of NPs}

Mammalian NPs (human/canine ANP and human $\mathrm{BNP}$ ) and eel VNP similarly relaxed the canine renal artery with a maximum relaxation of c. $10 \%$ at $10^{-7} \mathrm{M}$ (Fig. 5). Eel VNP, on the other hand, induced $30 \%$ relaxation at doses greater than $10^{-7} \mathrm{M}$ in the coronary artery. This vasorelaxant activity of VNP in the coronary artery was significantly greater than that of mammalian ANP and BNP. The vasorelaxant activity of VNP in the coronary artery was also significantly greater than that of VNP in the renal artery.

\section{Discussion}

In the present study, we have cloned cDNAs of four NPs (ANP, BNP, VNP and CNP) from a single sturgeon, thereby demonstrating for the first time that BNP and VNP are not orthologs but are coded by different genes. The sturgeon ANP may have an amidated C-terminus as predicted from the presence of a glycine residue prior to the stop codon. Sturgeon VNP was cloned from the ventricle, and is structurally highly homologous with eel and trout VNP, particularly in the long G-terminal tail sequence. Sturgeon GNP was isolated from the brain and lacks the tail sequence, as is the case in all CNPs thus far identified. The 


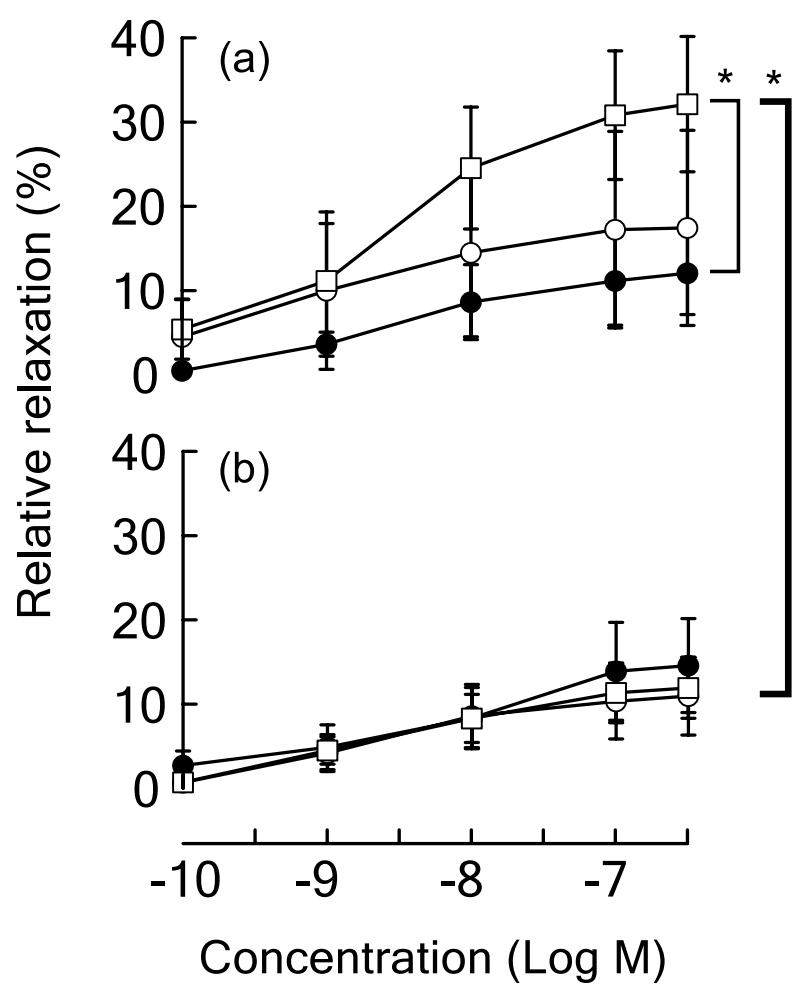

Figure 5 Vasorelaxant effects of NPs on dog coronary artery (a) and renal artery (b) in vitro ( $n=6$ each). $\square$, eel VNP; $\bullet$, human/dog ANP; $O$, human BNP. Changes in isometric tensions (means \pm S.E.) are expressed as a percentage of the maximal change. ${ }^{*} P<0.05$ by ANOVA.

tissue distribution of these NPs also supports our definition; ANP is almost exclusively expressed in the atrium, VNP in both atrium and ventricle, and CNP exclusively in the brain (Takei 2000).

In addition to ANP, VNP and CNP, we cloned BNP cDNA from the atrium of sturgeon. The sturgeon BNP satisfied all criteria for positive identification of BNP, in particular, the presence of seven AUUUA sequences in the 3'-untranslated region of the mRNA (Fig. 1). This characteristic has been found in all BNP mRNAs including chicken BNP (Akizuki et al. 1991). The presence of repeated AUUUA motifs is thought to facilitate mRNA degradation (Wilson \& Treisman 1988). The sturgeon BNP mRNA was expressed in both atrium and ventricle and some signal was also detected in the brain. The pattern of expression is consistent with that of the BNP gene in mammals (Sudoh et al. 1988, Yasue et al. 1994). Thus, it is obvious that BNP, which has been thought to exist only in tetrapods, does also exist in fish.
Since BNP is present in the chondrostean fish, we examined the existence of BNP in teleostean fishes. We chose the pufferfish, Takifugu rubripes, and tilapia, Oreochromis mossambicus, since they are widely cultured in Japan and the genome database of the pufferfish is now available. We successfully cloned BNP cDNA in addition to ANP from the heart of both species. The pufferfish and tilapia BNP possessed all characteristics of BNP as discussed for sturgeon BNP. Both pufferfish and tilapia ANPs may have amidated $\mathrm{C}$-termini as with sturgeon and eel ANP. Among all ANPs thus far identified, only eel ANP has an amidated C-terminus and the amidation is essential for cGMP production after binding with eel natriuretic peptide receptor-A (NPR-A) (Kashiwagi et al. 1999). The G-terminal amidation of ANP may have occurred generally since the amidation enzyme, peptidylglycine- $\alpha$ amidating monooxygenase, colocalizes with ANP in the same granules of the rat atrial cardiocytes although rat ANP is not C-terminally amidated (O'Donnell et al. 2003). The C-terminal glycine residue might have changed during the evolution to tetrapods as observed in trout ANP (Fig. 2a).

Sturgeons (Acipenseriformes) have generally been considered as a polyploid fish group (Fontana 1994, Birstein et al. 1997). Therefore, multiple orthologs of a particular peptide may exist in their genome. In fact, multiple molecules have been identified in growth hormone (Yasuda et al. 1992) and gastroenteropancreatic hormones (Kim et al. 2000). In these studies, the homology between the orthologs is generally high, e.g. only three amino acids out of 190 residues are substituted between two growth hormone sequences. In contrast, the homology between sturgeon BNP and VNP precursors is only $27 \cdot 2 \%$ in the present study. Similarity between BNP and VNP is low even in the mature peptides. Further, similarity between sturgeon BNP and VNP is much lower than that between sturgeon and other BNPs and between sturgeon and teleost VNPs. These results suggest that the four NPs found in Acipenser transmontanus originate from distinct genes.

Our classification of newly identified NPs is supported by the molecular phylogenetic analysis; all NP precursors identified in the present study were grouped in the respective NP species. The definition of teleostean BNP is further confirmed by the chromosomal localization. It is known that the BNP gene is localized in tandem with the ANP 
gene on the same chromosome in human and mouse (Tamura et al. 1996). We could not identify the ANP gene in the genome database of Takifugu rubripes, but we could find ANP and BNP genes on the same contig $(5216 \cdot 2)$ of another pufferfish, Tetraodon nigroviridis. BNP has not been identified thus far in the eel and salmonids, and the VNP gene was not detected in the pufferfish genome database. Therefore, it remains undetermined whether VNP and BNP coexist in the teleostean species or not. One possibility is that one of the two genes has been selected during teleostean evolution; BNP was chosen in pufferfish and tilapia, while VNP remained in eel and trout.

The current finding that BNP and VNP are coded by different genes allows us to suggest the possibility that VNP exists in tetrapods. In fact, eel VNP relaxed canine coronary artery more potently than human ANP and BNP (Fig. 5). If VNP is present in mammals, homologous VNP may exhibit much more potent effects on the coronary artery than heterologous fish VNP (Takei 2000). Therefore, we subsequently searched for VNP in the human genome and expressed sequence tag databases, but a VNP-like sequence was not detected. It seems that some important amino acid residues that have been conserved in all NPs thus far sequenced have changed in the putative VNP. Recently, an NP-like material immunoreactive to antiserum raised against Dendroaspis NP (DNP), a new venom-specific NP (Schweitz et al. 1992), was detected in the heart and plasma of humans (Lisy et al. 2001, Richards et al. 2002). Immunoreactive DNP increases in the plasma of patients with failing hearts. Since antiDNP serum does not cross-react with human ANP, BNP and CNP, immunoreactive DNP may be a candidate for the fourth human NP. It remains to be determined whether immunoreactive DNP is a homolog of putative human VNP.

In conclusion, the present study showed that BNP and VNP are coded by different genes in the sturgeon, which further leads to the identification of $\mathrm{BNP}$ in teleostean fish. The identification of BNP in ray-finned fishes further allowed us to suggest that VNP might be present in tetrapods including mammals. A potent vasorelaxant activity of eel VNP in the canine coronary artery supports the possible existence of VNP in mammals. Identification of more NPs in other primitive fishes and tetrapods will enable us to delineate more clearly the process of molecular evolution of the NP family.

\section{Acknowledgements}

The authors thank Dr Howard A Bern of the University of California at Berkeley for critical comments. We also thank Dr Yasuaki Takagi of Hokkaido University for his help in sampling sturgeon tissues, Dr Hiroaki Miyazaki and Ms Sanae Hasegawa of Ocean Research Institute, University of Tokyo for providing the tilapia, and Oita Biological Technology Center, Nippon Suisan Kaisha for providing the pufferfish.

\section{Funding}

This work was supported in part by a Grant-in-Aid for Creative Basic Research (12NP0201) from the Ministry of Education, Culture, Sports, Science and Technology of Japan, and for Scientific Research (13304063) from the Japan Society for the Promotion of Science to $\mathrm{Y}$ T. A $\mathrm{K}$ was supported by a Research Fellowship awarded by the Japan Society for the Promotion of Science for Young Scientists.

\section{References}

Akizuki N, Kangawa K, Minamino N \& Matsui H 1991 Cloning and sequence analysis of complementary DNA encoding a precursor for chicken natriuretic peptide. FEBS Letters $\mathbf{2 8 0}$ 357-362.

Bemis WE, Findeis EK \& Grandel L 1997 An overview of Acipenseriformes. Environmental Biology of Fishes 48 25-71.

Birstein VJ, Hanner R \& DeSalle R 1997 Phylogeny of the Acipenseriformes: cytogenetic and molecular approaches. Environmental Biology of Fishes 48 127-155.

Brenner BM, Ballermann BJ, Gunning ME \& Zeidel ML 1990 Diverse biological actions of atrial natriuretic peptide. Physiological Reviews 70 665-699.

Chen HH \& Burnett JC Jr 1998 C-type natriuretic peptide: the endothelial component of the natriuretic peptide system. Fournal of Cardiovascular Pharmacology 32 S22-S28.

Chomczynski P \& Sacchi N 1987 Single-step method of RNA isolation by acid guanidium thiocyanate-phenol-chloroform extraction. Analytical Biochemistry 162 156-159.

Evans DH 1990 An emerging role for a cardiac peptide hormone in fish osmoregulation. Annual Review of Physiology 52 43-60.

Farrell AP \& Olson KR 2000 Cardiac natriuretic peptides: a physiological lineage of cardioprotective hormone? Physiological and Biochemical Zoology 73 1-11.

Fontana F 1994 Chromosomal nucleolar organizer regions in four sturgeon species as markers of karyotype evolution in Acipenseriformes (Pisces) Genome 37 888-892.

Inoue JG, Miya M, Tsukamoto K \& Nishida M 2003 Basal actinopterygian relationships: a mitogenomic perspective on the phylogeny of the 'ancient fish'. Molecular Phylogenetics and Evolution $26110-120$. 
Kashiwagi M, Miyamoto K, Takei Y \& Hirose S 1999 Cloning, properties and tissue distribution of natriuretic peptide receptor-A of euryhaline eel, Anguilla japonica. European Fournal of Biochemistry $259204-211$.

Kawakoshi A, Hyodo S \& Takei Y 2001 CNP is the only natriuretic peptide in an elasmobranch fish, Triakis scyllia. Zoological Science $\mathbf{1 8}$ 861-868.

Kawakoshi A, Hyodo S, Yasuda A \& Takei Y 2003 A single and novel natriuretic peptide is expressed in the heart and brain of the most primitive vertebrate, the hagfish (Eptatretus burgeri). Fournal of Molecular Endocrinology 31 209-220.

Kim JB, Gadsboll V, Whittaker J, Barton BA \& Conlon JM 2000 Gastroenteropancreatic hormones (insulin, glucagon, somatostatin, and multiple forms of PYY) from the pallid sturgeon, Scaphirhynchus albus (Acipenseriformes). General and Comparative Endocrinology 120 353-363.

Lisy O, Lainchbury JG, Leskinen H \& Burnett JC 2001 Therapeutic sections of a new synthetic vasoactive and natriuretic peptide, Dendroaspis natriuretic peptide, in experimental severe congestive heart failure. Hypertension 37 1089-1094.

Loretz CA \& Pollina C 2000 Natriuretic peptides in fish physiology. Comparative Biochemistry and Physiology 125 169-187.

O’Donnell PJ, Driscoll WJ, Back N, Muth E \& Mueller GP 2003 Peptidylglycine- $\alpha$-amidating monooxygenase and pro-atrial natriuretic peptide constitute the major membrane-associated proteins of rat atrial secretory granules. Fournal of Molecular and Cellular Cardiology 35 915-922.

Richards AM, Lainchbury JG, Nicholls MG, Cameron AV \& Yandle TG 2002 Dendroaspis natriuretic peptide: endogenous or dubious? Lancet 359 5-6.

Schweitz H, Vigne P, Monier D, Frelin C \& Lazdunski M 1992 A new member of the natriuretic peptide family is present in the venom of the green mamba (Dendroaspis angusticeps). Fournal of Biological Chemistry 267 13928-13932.

Sudoh T, Kangawa K, Minamino N \& Matsuo H 1988 A new natriuretic peptide in porcine brain. Nature 332 78-81.

Suzuki R, Togashi K, Ando K \& Takei Y 1994 Distribution and molecular forms of C-type natriuretic peptide in plasma and tissue of a dogfish, Triakis scyllia. General and Comparative Endocrinology 96 378-384.

Takei Y 2000 Structural and functional evolution of the natriuretic peptide system in vertebrates. International Review of Cytology 194 $1-66$.

Takei Y \& Hirose S 2002 The natriuretic peptide system in eels: a key endocrine system for euryhalinity? American fournal of Physiology 282 R940-R951.

Takei Y, Takahashi A, Watanabe TX, Nakajima K \& Sakakibara S 1991 A novel natriuretic peptide isolated from eel cardiac ventricles. FEBS Letters 282 317-320.

Takei Y, Takano M, Itahara Y, Watanabe TX, Nakajima K, Conklin DJ, Duff DW \& Olson KR 1994 Rainbow-trout ventricular natriuretic peptide - Isolation, sequencing, and determination of biological activity. General and Comparative Endocrinology $96420-426$

Tamura N, Ogawa Y, Yasoda A, Itoh H, Saito Y \& Nakao K 1996 Two cardiac peptide genes (atrial natriuretic peptide and brain natriuretic peptide) are organized in tandem in the mouse and human genomes. Fournal of Molecular and Cellular Cardiology 28 1811-1815.

Wilson T \& Treisman R 1988 Removal of poly (A) and consequent degradation of c-fos mRNA facilitated by $3^{\prime}$ AU-rich sequences. Nature 336 396-399.

Yasuda A, Yamaguchi K, Noso T, Papkoff H, Polenov AL, Nicoll CS \& Kawauchi H 1992 The complete amino acid sequence of growth hormone from sturgeon (Acipenser guldenstadti). Biochimica et Biophysica Acta 1120 297-304.

Yasue H, Yoshimura M, Sumida H, Kikuta K, Kugiyama K, Jougasaki M, Ogawa H, Okumura K, Mukoyama M \& Nakao K 1994 Localization and mechanism of secretion of B-type natriuretic peptide in comparison with those of A-type natriuretic peptide in normal subjects and patients with heart failure. Circulation 90 195-203.

Received 15 September 2003 Accepted 19 November 2003 